\title{
PENITENTIARY PROGRAMS - POSSIBILITIES AND LIMITATIONS IN THE OPINION OF PENAL OFFICERS - METHODICAL GUIDELINES
}

\section{Ilona Fajfer-Kruczek}

\begin{abstract}
Correctional-penitentiary programs are nowadays a basis for the impact of social rehabilitation in penal institutions. The article presents the sense and assumptions of the creation and implementation of correctional programs, as well as some selected opinions of officers on the implementation and effectiveness of the programs. The final part of the article includes methodical and didactic guidelines
\end{abstract}

\section{Keywords}

penal institution, readaptation, social rehabilitation, prison

\section{Introduction}

Interactions with incarcerated individuals, called the social rehabilitation interactions, are heterogeneous in their specificity, theoretical assumptions, methods, and used techniques. However, those various methodological actions have the same goals - a change in behavior, personality, approaches, motivation and habits of the incarcerated individuals so that they would not commit further criminal offences. As stated by (Majcherczyk 2013, p. 195) "imprisonment without elements of rehabilitation does not make any sense." On the one hand, actions of social rehabilitation nature, determining the manner of the punishment in the Polish administration of justice, have a utilitarian significance and therefore may affect its measure, whereas on the other hand, they relate to individual prevention and criminological prognosis. By referring to the function of imprisonment, A. Jaworska indicates that a legislation assumption saying that the penalty of absolute imprisonment gives optimal opportunities for the social rehabilitation of the incarcerated individuals is not reflected in the study results, although the isolation itself, without social rehabilitation interactions, would constitute a departure from penitentiary work with the incarcerated in general. 
The legal basis determining the rules and procedures of implementing correctional and therapeutical interactions is defined in The Executive Penal Code (Journal of Laws no. 90, item 557, Art. 95-96, Art. 249a) and particularly The Regulation no. 19/16 of the Director-General of the Prison Service dated on 14th April 2016 concerning the detailed rules of conducting and organizing penitentiary work and the scope of activities of officers and employees of penitentiary and therapeutic departments and penitentiary divisions.

This article says about the basic theoretical assumptions to create and implement correctional programs, their conditions and provides the review on opinions of managers and correctional educators about their implementation as well as methodological guidelines for certain elements of a correctional program.

\section{Terminological assumptions}

Criminogenic and social maladjustment factors are most often indicated as passive and dynamic. The former comprise some kind of a fact that cannot be changed but which may serve for the purpose of explaining the mechanism of a certain, undesirable behavior - as the example one may give a process of growing up in a dysfunctional family. Understanding and identification of criminogenic factors in the history of life of certain incarcerated individuals seem to be essential and even necessary for adequate and effective social rehabilitation interactions. It is then not sufficient to be aware of their existence but also about their manner and the dynamics with which they directly or indirectly affect people subject to penalization. All the more some static and dynamic factors are related with each other, where the latter may result from the former. There are various reasons for coming into conflict with the law, but one should bear in mind that the incarceration in the correctional system fulfills a few functions at the same time (insulating, deterrent, retaliatory, compensatory, corrective) (Ciosek, 2001, p. 176-178), and its main goal is of a primary nature: counteracting return to crime, return to society and proper functioning (social readaptation) and protection of society against crime (Tadla, 2003, p. 176).

Criminogenic factors, type of the committed crime, as well as the specific features of the incarcerated individuals shall be taken into account when constructing a principle related to the appropriate system of serving the sentence of imprisonment, as well as the methods of rehabilitation, therapy and preventive actions (Kwieciński, 2013). And although in the correctional practice the concept of "penitentiary interaction" is abandoned and replaced with a term 'program' (Jaworska, 2008, p.100), one should bear in mind that the former refers to professional actions taken both in the scope of the program and beyond it, i.e. a personal impact (motivating conversation) and others. The literature defines the social rehabilitation program as '(...) the social rehabilitation program which is focused on the change in dynamic criminogenic factors and thus it directly serves the implementation of a superior goal of the imprisonment, i.e. preventing the return of the incarcerated person to a crime (Majcherczyk, 2013, p. 195). This definition is very consistent and the same as the purpose of imprisonment.

The common understanding of social rehabilitation, as institutional, one-sided action raises the argument that responsibility for success and failure lies with the social rehabilitators, 
not the subjects of their influence. Therefore I suggest to adopt a working definition of a program, which is a methodically designed set of tasks creating situations (in certain time and space), in order to evoke specific inter - and intra - interactions, reactions, and inter - and intrapersonal processes. Creation of optimal conditions and opportunities to induce and consolidate the desired behavior and properties of inmates.

One should also pay attention to the specific factors of success or the failure of correctional social rehabilitation programs which A. Majcherczyk founds as 'the features of the program itself, properties of the interveners (change agents), personality of the incarcerated included in the program, type of the problem subject to the remedy, a manner of the program implementation into practice, features of the institution in which the program is used, etc. Factors of effective social rehabilitation according to D.A. Andres (1995) and J. Bont (1997) based on the following programs (for: Ciosek, 2009, p. 333-334; Jaworska, 2008, p. 96-98):

- a degree of hazard related to the return to crime - correctional programs should be directed to the incarcerated at a middle and high level of risk within returning to criminal activity;

- individual criminogenic factors which determine the needs of social rehabilitation attitudes, cognitive deficits, deficits in emotional, social and intellectual development; - adapting the program to the capabilities of the incarcerated individuals and motivating them to participation and change;

- freedom of action of penitentiary staff - possibility of making decisions on the basis of one's own competences, assessment of the situation without the interference of superiors;

- program integrity - programs should be implemented in accordance with theoretical assumptions of multidimensional and individualized, flexible character.

One of the most general conclusions which one may draw when trying to sum up the knowledge on penitentiary social rehabilitation conditions, is they care about the program quality (reference to the theory, accuracy of the assumed goals and effects, schedule, staged structure of actions, idea), the quality of its implementation into practice (staff potential - qualifications and scope of activity (especially as it results from the assumption and practice where the authors of most programs are penitentiary officers (Froelich, 2008, p. 70-71), selection of participants, preparation of appropriate background, flexibility, financing, external support) and creation of appropriate institutional conditions, cooperation of various divisions (institution's climate, institutional resources). As stated by (Froelich, 2008, p. 75), "(...) implementation of programs does not meet all social rehabilitation expectations". (Dubiel, 2008, p. 107) in turn indicates in his works that some present penitentiary interactions are not of a social rehabilitation character and serve only to the 'reduction of the tense among the incarcerated and creation of the system safety valves'. In his considerations, (Górny, 1996, p. 69) indicated the awareness of contradiction lying in the concept of imprisonment itself and in manners of its performance as well as the factors hindering or even preventing the achievement of social rehabilitation purposes which are included in the provisions of criminal law. The negative effects of penitentiary isolation are dominant, however, as stated by (Poklek, 2010, p. 71-73), there are also some positive effects, like e.g. 
satisfying the most important needs among the incarcerated, possibility of healthcare, rehabilitation, abstinence and actions of a therapeutical and social character which are included in the programs.

\section{Methodological assumptions}

The aim of the study was to determine the feeling of competence within creating and implementing penitentiary programs among correctional educators, as well as a diagnosis of methodological support needs and the opinion on the conditions for effectiveness. The main research problem was contained in the question. What are the experiences and opinions of educators penitentiary in implementing programs penitentiary? The study was conducted in cooperation with the Regional Directorate Prison Service in Katowice in subordinate units in 2018 during two trainings and methodological conferences at the University of Silesia - Faculty of Ethnology and Educational Sciences in Cieszyn. At this time a diagnostic survey has been used (survey - educators, penitentiary managers). In total, 56, completely fulfilled survey questionaries were collected. The study conducted among officers from the Regional Inspectorate of the Prison Service in Katowice included mostly men (50); there were only 6 women subjected to the study. The study sample has been shown in the table 1 , in juxtaposition with regard to sex, average age of respondents, length of service and average number of implemented correctional programs. Unfortunately, due to a clear disproportion in terms of gender, there is no basis for comparison and formation of unequivocal statements as to the degree of involvement in the implementation of programs by women and men. Opinions of correctional educators and managers on the programs' subject matter.

The specificity of working in a penitentiary unit and direct passage of the provisions on the requirement to implement programs prompts each respondent to implement at least one program. In the questionnaires, some respondents also indicated the total number of programs implemented, as well as the number of programs currently implemented by them in person. The opinion shows that one educator carries out from 1 to 8 programs simultaneously. It is difficult to guess whether the number of the conducted programs is reflected in their effectiveness as there is no such information resulting from data, yet we may assume that this situation requires both good organization of work and a range of specialistic qualifications within the program conduction and management.

\section{Table 1}

\begin{tabular}{|l|c|c|c|}
\hline \multicolumn{1}{|c|}{ Sex } & $\begin{array}{c}\text { The average age } \\
\text { (in years) }\end{array}$ & $\begin{array}{c}\text { The average length } \\
\text { of work in the } \\
\text { Prison Service } \\
\text { (in years) }\end{array}$ & $\begin{array}{c}\text { The average } \\
\text { number of } \\
\text { programs } \\
\text { conducted by } \\
\text { 1 person }\end{array}$ \\
\hline Women $(\mathrm{Nk}=6)$ & 34 & 5.6 & 3 \\
\hline Men $(\mathrm{Nm}=50)$ & 37 & 10.7 & 8 \\
\hline
\end{tabular}

Source: the author's own study 
The most frequently indicated obstacles/difficulties in the effective implementation and efficiency of the penitentiary programs, indicated by the surveyed correctional educators and managers, have been shown in the Table 2. The respondents' task was to indicate obstacles and difficulties in their own words, the statements were grouped thematically and cited as examples. As it results from the collected data, the surveyed officers refer to their own limits, which in their opinion result mostly from the lack of time and being burdened with obligations and procedures, which is certainly reflected in the time spent on preparation, implementation, and evaluation of the implemented programs. Another important issue presented by the surveyed is the insufficient financing of programs and insufficient infrastructure, certainly one may say that some interactions do not require any additional measures to be taken as the penitentiary staff consists of mainly qualified pedagogues, although both infrastructure and methodological preparation are significant in terms of motivating the incarcerated and any insufficiencies may prove the apparent professionalization of activities. Other, no less important, but less frequently mentioned difficulties are those related to motivating the incarcerated to changes and generally to their participation in the programs, as well as issues related to the rotation of the incarcerated, difficulties in the programs implementation in pretrial detention centers, long waiting for addiction therapies. In view of the above, the officers treat the interactions through the programs as an additional obligation, jeopardized by the risk of effectiveness in the absence of sufficient time for preparation and implementation and resulting from the non-adaption of the penitentiary system in the scope of financing and infrastructure to the real effectiveness of such activities. 


\section{Table 2}

\section{Obstacles and difficulties in the implementation and effectiveness of the social rehabilitation programs in the opinions of the Prison Service representatives.}

Number of indications

Lack of time

Educators being burdened with paperwork (bureaucracy)

Insufficient financial means (for remuneration, new employees, materials for the implementation of the programs, inadequacy of means designed for the program assumptions)

Insufficient infrastructure (lack of premises, lack of base, architectural limitations, equipment, etc.)

Protection procedures (difficulties in possibility to use props, didactic help, individualization of interactions, time of classes, etc.) Lack of involvement among the incarcerated (apparent voluntariness, doubtful motivation to implement program classes and others).

Others: lack of understanding among the incarcerated, apparent program implementation, incomplete program cycle, no specialistic courses finished by the educators; length of waiting for the addiction therapy programs, insufficient cooperation with the art. 38, rotation of the incarcerated and others

Source: the author's own study

Among different types and forms of social rehabilitation interactions, the respondents indicated the following types as the most effective: paid and unpaid work (57 persons), addiction therapy programs (40 persons), programs about handling stress and anger and programs of work with perpetrators of domestic violence (23 persons); as well as other types and forms of social rehabilitation interactions implemented as a part of cultural and educational classes, programs based on sport, religious meetings, talks based on a motivational dialogue, programs orientated for relations with family and volunteering. It is assumed that such a perception of effectiveness is the result of social beliefs about the natural activity of adults through paid work or as an activity in action in general, as well as standardized observations and unified programs, although most of the implemented programs are of an original character, in particular under the assumption that the program is dedicated to particular group. It is worth noting that 12 people have indicated again that the participation in the correctional programs is often apparently voluntary, and the participants' motivation is sometimes nonsubstantive and instrumental.

Another issue related with the implementation of programs is the evaluation, often identified with estimation of the effectiveness. According to the assumptions of the social 
rehabilitation and the program goals, the effects prove the effectiveness. However, it is difficult to determine in conditions of isolation how the person previously subject to penalty will behave in conditions of freedom and what kind of choice they will eventually make. Internalization of norms and values, apart from gaining a binding knowledge about mechanisms of undesirable phenomena, the causality of events, the effects of crime, as well as building social competences are mostly beyond external influences. However, formal actions should have a raison d'être (reason for existence) and should be monitored in order to be effective. The surveyed group was asked to precise in what way they evaluate programs, the vast majority indicated that they use a survey as a tool to do it (43 respondents), tests - including tests on knowledge - 6 respondents, 2 respondents indicated the work results. It points out to a real possibility of reference to measurable indicators, but rather to the opinions of the program participants, not to the assessment of knowledge or skills. 42 officers working in the region of Katowice indicated their need for methodological and substantive support in the creation and realization of penitentiary programs, among others: exemplary, sample programs, methodological guidelines, manuals, substantive consultations, bibliographic lists, external partners, workshops and trainings. What is more, 34 respondents have estimated their own competencies to create original programs as sufficient, 12 - as insufficient, 7 respondents have estimated their own competencies in this field as very strong, 2 respondents have given the answer 'I don't know'.

Instead of conclusion - selected elements of the correctional program - methodological hints

Below, general guidelines for the methodical preparation of correctional programs are presented, from the indication of didactic principles to practical guidelines.

1. The program manager should be clearly identified - especially the coordinator. The program should be carried out individually, e.g. by an educator or by a team. Important people who may be partners or managers.

2. Subject matter of the program along with a brief justification of the importance of the actions taken. Short description of theoretical background for the planned activities along with indication the program type and role.

3. Characteristics of the population of incarcerated individuals, which may be determined by:

- categories of the incarcerated; juveniles, individuals serving a sentence for the first time, penitentiary recidivists;

- criteria and rules based on: negative diagnosis of deficits (who can and who cannot participate in the program), the Individual Program of Interactions (indications), length of the sentence still to be served, the educator's opinion, the psychologist's opinion, positive diagnosis (certain skills, motivation, qualifications); qualification of participants - the Penitentiary Commission;

- number of participants; for logistical and organizational reasons as well as the substantive premises, the number of participants should be indicated - total, in a group, in the edition (minimum-maximum). 
It is worth referring to the rule of a voluntary act. The expressed willingness to participate is binding, as is the written request of the inmate, although, as indicated by the opinions of officers of the penitentiary division, the motivation to join is sometimes non - substantive.

4. The penitentiary program description should include in a more or less complex way the main goal, place of performance, period of duration, methods

5. and techniques of interactions, materials and educational measures that are necessary for the program implementation. Within the social rehabilitation interaction it is preferred to define long-term goals (in particular: to reduce the risk of returning to crime, bad habits, risk and destructive behaviors, change in social identity, social reintegration, elimination of criminogenic factors)

6. and short-term goals - verification in the course of and after the completion of the program in an unit: behavior modification, emotional reconstruction, shaping correct social attitudes) (Jaworska, 2012).

The main aim should be real, measurable and should refer to the subject matter of the correctional program and the effect to be achieved.

Specific objectives should refer to the detailed operational effects that make up the achievement of the specific objective. They should be formulated in accordance with the assumed and verified effects in the scope of knowledge, skills and attitudes/ competences.

Place of performance is usually a penitentiary unit (taking into account e.g. specific departments, a space where the planned activities may take place: common-room, lecture, computer, therapeutical halls, study rooms, social premises, workshops, openair space and other); and/or e.g. an institution (the place where a program or its part is carried out outside the unit, i.e. hospice, animal shelter, etc.).

Duration is specified by a schedule which determines the total length of the program implementation together with evaluation, including certain stages and frequency and the time of duration of certain activities.

Methods and techniques of interactions should be formulated according to the conceptual terminology, e.g. assimilating, emotional or operative methods; or anthropotechnics, social engineering, culture engineering; or one's own work individual and teamwork - work in groups (free, random, purposeful).

Educational materials and measures necessary for the purpose of the program implementation, are used to determine the resources and direct costs of the program, as well for the purpose of its effective implementation.

The most frequently used methods and techniques: lecture, talk, reading, show, presentation, audiovisual methods, projection and/or recording of a film, music, group work, role-playing, training, professional workshops, creative workshops, activating methods, methods in recreational and sports activities. Materials, didactic aids worth thinking about when planning and verifying the unit's resources and budget include content sources, literature, script, props, multimedia presentation, computer hardware, software, audio, video, photo equipment, dictaphone, course scenarios (instructions), solution sheets, teaching materials - teaching aids, demonstration models, specialist equipment, sports equipment, games, instructions. 
7. Manner of implementation - the proper program is a description of the course and the idea. This part may be formulated by indicating e.g. the modules - a series of classes reflecting the next level of involvement, skills, knowledge: stages a series of classes for one or more groups, particularly facilitating the description and organization of the program of which effect is to obtain certificates, degrees of improvement, creation of work, implementation of system: meetings chronologically ordered, e.g. numbered descriptions of successive meetings in a series of the program together with the description of the course - they do not have to be related to each other by the participation in the previous ones.

Another way to present the correct assumptions of the program is a manner of implementation according to groups, e.g. educational and training group (language groups - educational program level description), therapeutical group: psychotherapeutic - description of activities, sociotherapeutical group - description of activities, support group - description of activities.

Another possibility to present the form of the program implementation is the manner of interactions - e.g. - preventive classes, therapeutical classes, educational classes, sport/recreation activities (tournaments, competitions), stages of advancement, artistic classes, e.g. rehearsals, play, animation, exhibition, concert, recording, individual consultancies for participants. Other types of the program implementation form: competition, visit, trip, etc.

It is important to attach scenarios/synopses for certain stages, classes.

8. Evaluation process outline. "Evaluation is the process of systematical gathering of information about actions, properties and effects of the programs, staff and products which are used by specialist to reduce uncertainty around the program and improve its efficiency, and help make decisions about what the programs, personnel or products do and what they relate to (Robson, 1997, p. 152).

9. Evaluation of the penitentiary program may be - internal, conducted by the program managers (at every stage, individually by every manager, coordinator) or other staff, including in particular the penitentiary manager, the Penitentiary Commission. External evaluation - allows to objectively determine the course and effectiveness of the program. The evaluation should not be any form of control, it should serve as a support for managers, modification or creation of new programs which take into account the resources and hindering factors (Marczak, Pawełek, 2009). In the process of evaluation, it is difficult to determine the effectiveness of the program when participants simultaneously participate in the programs with similar purposes at the same time or they have participated in such programs in the other units in a shorttime period. A list of goals should be formed already at the stage of planning - effects and possibilities of their verification, evaluation, documentation with considering the time, measures and human resources appointed for these tasks. Methods of evaluation: surveys, tests, rating scales, verification interviews, observations, notes and protocols, attendance sheets, documentation; moving to the next module/stage/ level, obtaining a certificate, statistics: number of people trained, number of people who completed skill training, therapy series; results of work, artistic works, opinion of educators, psychologists and others. 
Finally, it is worth pointing out to the triad of the social rehabilitation program that determines its effectiveness - the idea and preparation of the program, implementation and involvement of its participants.

The methodological recommendations themselves, in reference to the preparation of the penitentiary program, are not a warrant for its effectiveness, yet the awareness of certain elements in the process of planning makes it possible to achieve goals, motivates the officers to draft lists of human and material resources as well as of formal and procedural difficulties, time limits. What is more, the involvement of educators increases a chance for the program interaction success as it enables interaction between staff and participants, particularly in the aspect of motivating to create one's own image, change of attitudes, influencing one's current well-being.

\section{References}

Ciosek, M. (2001). Court and petitentiary psychology (pp. 176-178). Warsaw: The Publishing House Wydawnictwo Naukowe PWN.

Dubiel, K. (2008). A prison - total or social rehabilitation institution? In M. Kuć (Ed.), Criminological and penitentiary aspects of the execution of imprisonment. Lublin: Towarzystwo Naukowe KUL.

Froelich, A (2008). Selected programs of social rehabilitation interactions, In H. MalickaGorzelańczyk, P. Prusak, In search of alternative methods of social rehabilitation of the incarcerated. (pp. 70-71). Bydgoszcz: Wydawnictwo Kujawsko-Pomorskiej Szkoły Wyższej.

Górny, J. (1996). Elements of individualization and humanization of punishment in the development of penitentiary. Warsaw: WSPS.

Jaworska, A. (2012). The Lexicon of social rehabilitation. Cracow: The publishing house Oficyna Naukowa IMPULS.

Jaworska, A. (2008). Methods of interactions in the Polish penitentiary model. In A. Jaworska (Ed.) Criminology and criminal punishment. Cracow: Oficyna Wydawnicza "Impuls",

Kwieciński A. (Ed.). (2013). Proceedings with selected groups of convicts in the Polish penitentiary system. Legal aspects. Warsaw: Wolters Kluwer.

Majcherczyk A. (2013). Projecting and implementation of social rehabilitation program. In P. Szczepaniak (Red.). The Polish penitentiary system. Integral and cultural approach. Warsaw: The Publishing House Wydawnictwo Forum Penitencjarne. 
Marczak M., Pawełek K. (2009). Conclusion. From designing the evaluation: a few words about effectiveness of the programs implemented towards the incarcerated individuals. In M. Marczak (Ed.) Correctional social rehabilitation programs implemented by the Prison Service in Poland. Cracow: Oficyna Wydawnicza "Impuls".

Poklek, R. (2010). Institutional and psychosocial aspects of the prison, Central Training Center of the Prison Service. Kalisz.

Robson C. (1997). Designing evaluation. In L. Korporowicz (Ed.) Evaluation in education. Warsaw: Oficyna Naukowa.

Tadla R. (2003). Deprivation of liberty - factors that hinder effective social rehabilitation. Probation, 4.

The Executive Penal Code dated on 6th June 1997 (Journal of Laws no. 90, item 557).

The Regulation no. 19/16 of the Director-General of the Prison Service dated on 14th April 2016 concerning the detailed rules of conducting and organizing penitentiary work and the scope of activities of officers and employees of penitentiary and therapeutic departments and penitentiary divisions. Retrieved from http://edu.cossw.pl/mod/book/ view.php?id=2637\&chapterid $=1683$

[date of access: 13.06.2019].

\section{Author}

dr Ilona Fajfer-Kruczek

Institute of Pedagogy

University of Silesia in Katowice

Bielska 62, 43-400 Cieszyn, Poland

ilona.fajfer-kruczek@us.edu.pl 